\title{
Sistem Informasi Rekam Medis Berbasis Web Pada Puskesmas Rasau Jaya Pontianak Menggunakan Framework Laravel 5.6
}

\author{
Lady Agustin F F $^{1}$ Abdul Latif ${ }^{2}$, Ali Mustopa ${ }^{3}$, Ahmad Fachrurozi ${ }^{4}$ \\ 1,2,3,4 STMIK Nusa Mandiri Jakarta \\ e-mail: ${ }^{1}$ lady.lag@ bsi.ac.id, ${ }^{2}$ abdul.bll@bsi.ac.id, ${ }^{3}$ alimustopa.aop@bsi.ac.id, ${ }^{4}$ ahmad.ach@bsi.ac.id

\begin{tabular}{ccc}
\hline Diterima & Direvisi & Disetujui \\
$13-12-2019$ & $15-12-2019$ & $17-12-2019$ \\
\hline
\end{tabular}

\begin{abstract}
Abstrak - Era komputerisasi saat ini membuat dunia kesehatan memanfaatkan teknologi untuk kegiatan yang ada di rumah sakit maupun puskesmas. Namun pada sistem rekam medis yang sedang berjalan dipuskesmas terdapat kekurangan yang menghambat proses rekam medis dibagian pelaporan kunjungan terbanyak menggunakan perhitungan data-data secara langsung dengan melihat data sebelumnya yang sudah dicetak dan penyimpanan identitas pasien dicetak dan diarsipkan kedalam folder. Maka diperlukanlah sistem yang dapat memudahkan agar keakuratan data lebih terjamin dan adanya sistem maka pelayanan menjadi lebih efektif. Dalam pembuatan rekam medis ini, penulis menggunakan framework laravel yang memudahkan programmer dalam membuat dan mengembangkan aplikasi karena memiliki fungsi-fungsi yang sudah di organisasikan untuk membuat program dengan cepat. Buku yang berjudul "Sistem Informasi Rekam Medis (SIRAM) dengan LARAVEL 5.6" ini menjelaskan langkah membuat aplikasi,dimulai dari analisis kebutuhan, rancangan diagramnya seperti use case, activity diagram, ERD dan LRS, class diagram, sequence diagram, serta rancangan lengkap aplikasi seperti rancangan form master, pengolahan rekam medis dan laporan. Buku ini juga membuat kebutuhan dari pengguna aplikasi rekam medis dimana penggunanya terdapat beberapa user yang dapat menjalankan fungsi-fungsi sesuai dengan kebutuhannya.
\end{abstract}

Kata Kunci: Sistem Rekam Medis, Web Programming, Laravel

Abstract- The current computerized era makes the world of health use technology for activities in hospitals and health centers. However, in the ongoing medical record system in the health center there are deficiencies that hamper the medical record process in the most visited reporting section using the calculation of data directly by looking at the previously printed data and storing the patient's identity printed and archived into a folder. So we need a system that can make data accuracy more secure and the system is more effective. In making this medical record, the author uses a laravel framework that makes it easier for programmers to create and develop applications because they have functions that have been organized to make programs quickly. The book entitled "Sistem Informasi Rekam Medis (SIRAM) with LARAVEL 5.6" explains the steps to making an application. starting from needs analysis, diagram design such as use cases, activity diagrams, ERD and LRS, class diagrams, sequence diagrams, and complete application designs such as master form design, medical record processing and reports. This book also makes the needs of users of medical record applications where there are several users who can perform functions according to their needs.

Keywords: Medical Records, Web Programming, Laravel

\section{PENDAHULUAN}

Perkembangan teknologi komputer dan informasi Kalimantan Barat pada era saat ini sangat mempengaruhi dalam segala bidang baik dalam bidang pendidikan, pemerintahan, perkantoran, dunia kerja maupun didunia kesehatan. Tentunya kebutuhan informasi yang akurat dan efisien sangat diperlukan dalam pemanfaatan teknologi komputer dan informasi. Adanya kemajuan teknologi komputer dan informasi sekarang ini memberikan beberapa alternatif dalam mengolah data, salah satunya dengan menggunakan teknologi yang sudah tersistem komputerisasi. Sehingga dengan adanya sistem tersebut data dapat di akses dengan mudah dan cepat.

Salah satu dampak yang ditimbulkan pada tekonologi komputer dan sistem informasi pada saat ini yaitu dalam bidang kesehatan. Kesehatan merupakan hal terpenting yang harus di jaga oleh setiap manusia. Menjaga kesehatan adalah salah satu upaya yang harus di perhatikan karena hal tersebut akan mempengaruhi aktivitas dan kinerja diri sendiri maupun orang lain. Saat ini banyak orang yang selalu mengabaikan kesehatan diri sendiri karena dengan berbagai aktivitas dan kesibukan yang mereka lakukan. Akibatnya saat ini banyak puskesmas atau 
rumah sakit manapun terdapat banyak orang berobat kesana dengan berbagai keluhan dan penyakit yang bermacam-macam jenisnya. Seharusnya setiap orang mampu untuk merasakan bagaimana kesehatan dirinya sendiri. Dan apabila terserang suatu penyakit apapun harus mampu untuk merasakan keadaan tubuhnya dan bersegera untuk memeriksakan diri ke puskesmas atau rumah sakit yang terdekat.

Namun yang sangat disayangkan pada puskesmas Rasau Jaya Pontianak, kebutuhan terhadap sistem pengolahan penyimpanan data masih belum dilakukan secara terkomputerisasi. Sehingga hal tersebut tidak baik dari segi waktu maupun pelayanan. Begitu juga pencatatan rekam data medis pasien yang kurang maksimal, hal ini disebabkan minimnya sistem pencatatan yang handal untuk merekam semua data pemeriksaan pasien. Pencatatan data medis yang dilakukan tanpa menggunakan sistem yang terkomputerisasi sering kali terjadi kekurang terlitian manusia (human error). Maka diperlukan sesuatu sistem yang dapat membantu untuk permasalahan yang terjadi di puskesmas Rasau Jaya Pontianak.

Sistem informasi adalah suatu sistem dalam suatu organisasi yang mempertemukan kebutuhan pengolahan transaksi harian yang mendukung fungsi operasi organisasi yang bersifat manajerial dengan kegiatan strategi dari suatu organisasi untuk dapat menyediakan kepada pihak luar tertentu dengan informasi yang diperlukan untuk pengambilan keputusan (Gufroni et al., 2014).

Sedangkan Rekam Medik menurut Peraturan
Menteri 749a/MenKes/Per/XII/1989 adalah berkas yang berisikan catatan dan dokumen tentang identitas pasien, pemeriksaan, pengobatan, tindakan, dan pelayanan lain kepada pasien pada sarana pelayanan kesehatan. Rekam medik adalah siapa, apa, di mana dan bagaimana perawatan pasien selama di rumah sakit. Untuk melengkapi rekam medik harus dimiliki data yang cukup tertulis dalam rangkaian kegiatan guna menghasilkan suatu diagnosis, jaminan, pengobatan dan hasil akhir (SK Men PAN No. 135 tahun 2002).

\section{METODE PENELITIAN}

Pengembangan aplikasi secara terstruktur dengan menggunakan metode Waterfall pada tahapan Software Development Life Cycle (SDLC) meliputi: analisis, perancangan, pembuatan kode, pengujian, implementasi dan perawatan.

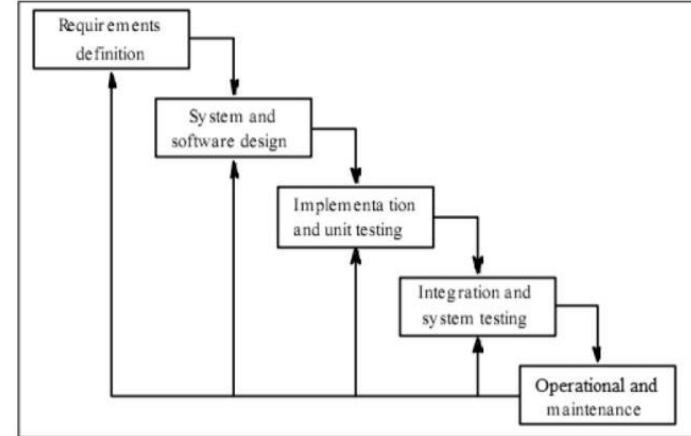

Sumber: Sommerville (2007:30)

Gambar 1. Model Waterfall

Berikut merupakan cakupan aktifitas menggunakan pendekatan Model Waterfall :

1. Analisis kebutuhan (analyzing)

Setelah komunikasi dengan pengguna, dilakukan analisis kebutuhan sistem, yang terdiri dari analisis kebutuhan penggguna, analisis kebutuhan fungsional sistem, analisis kebutuhan hardware dan software pada sistem yang akan dibangun.

2. Desain (design)

Melakukan perancangan terhadap sistem berdasarkan analisis kebutuhan yg sudah dilakukan sebelumnya.

3. Pembuatan kode (coding)

Tahapan ini merupakan tahap pengkodean (coding) untuk membangun aplikasi secara utuh. Setelah aplikasi selesai dibangun, aplikasi siap diserahkan kepada pengguna (user).

4. Pengujian sistem (testing)

Pengujian dilakukan setelah aplikasi selesai dibangun. Pengujian aplikasi bertujuan untuk mengetahui kesalahan-kesalahan yang mungkin terjadi jika aplikasi telah berada di tangan pengguna. 5. Implementasi (implementation)

Implementasi dilakukan setelah aplikasi lolos uji. Perangkat pendukung yang diperlukan tidak hanya hardware komputer, tetapi juga dukungan kebijakan, prosedur, pelatihan pengguna, dan sebagainya.

6. Perawatan (maintenance)

Aplikasi yang telah diimplementasi diharapkan dapat dipakai dan tidak berhenti di tengah jalan. Agar dapat dipergunakan terus menerus, perangkat lunak harus dipelihara dengan memperhatikan beberapa aspek, diantaranya:

a. Mampu menangani perkembangan data dikarenakan seiring berjalannya waktu.

b. Mampu menangani ancaman kerusakan oleh virus atau program penyusup lainnya.

c. Mampu menangani perbaikan apabila ditemukan error atau bug pada aplikasi yang sedang dijalankan.

d. Mampu menangani penambahan fitur baru.

e. Mampu menangani perkembangan dan kemajuan teknologi.

Teknik Pengumpulan Data 
a. Observasi

Observasi adalah suatu cara untuk mengumpulkan data dengan melakukan penelitian secara langsung datang ke Puskesmas Dayeuhkolot hal ini untuk mengamati dan pencatatan terhadap peristiwa yang sedang di selidiki pada objek penelitian.

\section{b. Studi Literatur}

Pada tahap ini, yang dilakukan adalah dengan membaca literature yang ada dan mencari literature tambahan yang dibutuhkan dalam pendalaman materi terhadap konsep dan teori web programming.

\section{c. Wawancara}

Suatu cara pengumpulan data melalui tanya jawab secara langsung antara peneliti (pengumpul data) dengan responden (sumber data), dalam hal ini wawancara dikakukan dengan responden yang berhubungan langsung pada sistem informasi pendaftaran pasien.

\section{HASIL DAN PEMBAHASAN}

Penelitian ini menghasilkan sebuah sistem berbasis komputer yang dibangun berdasarkan kebutuhan-kebutuhan sistem yang sudah didapatkan.

\section{A. Kebutuhan pengguna sistem}

Berdasarkan penelitian yang sudah dilakukan didapatkan 3 pengguna sistem yang dibangun, yaitu :

1. Administrator Sistem, yang bertugas mengelola sistem atau aplikasi tersebut.

2. Dokter, yang bertugas untuk menginput data antrian dan mengelola data pasien.

3. Apoteker,yang bertugas untuk mengelola data obat yang ada di puskesmas tersebut.

B. Kebutuhan Sistem

1. Pengguna aplikasi rekam medis melakukan login terlebih dahulu agar dapat mengakses atau menggunakan aplikasi rekam medis dengan memasukkan username, password yang telah dibuat agar privasi terjaga keamanannya.

2. Didalam sistem pengguna dapat melakukan penginputan data-data sesuai dengan kebutuhan si pengguna, serta masih banyak hal lain yang dapat dilakukan di sistem yang telah dibuat.

3. Sebelum keluar dari aplikasi, pengguna wajib melakukan logout agar aplikasi agar tidak disalah gunakan oleh oknum yang tidak bertanggung jawab.

C. Perancangan Sistem

Dalam melakukan perancangan sistem, peneliti menggunakan tools Diagram Usecase, ERD, dan Class Diagram yang digunakan untuk mengetahui fungsi apa saja yang ada di dalam sebuah sistem dan siapa saja yang berhak menggunakan fungsi-fungsi tersebut.

1. Use Case Diagram
Berikut hasil rancangan menggunakan diagram usecase:

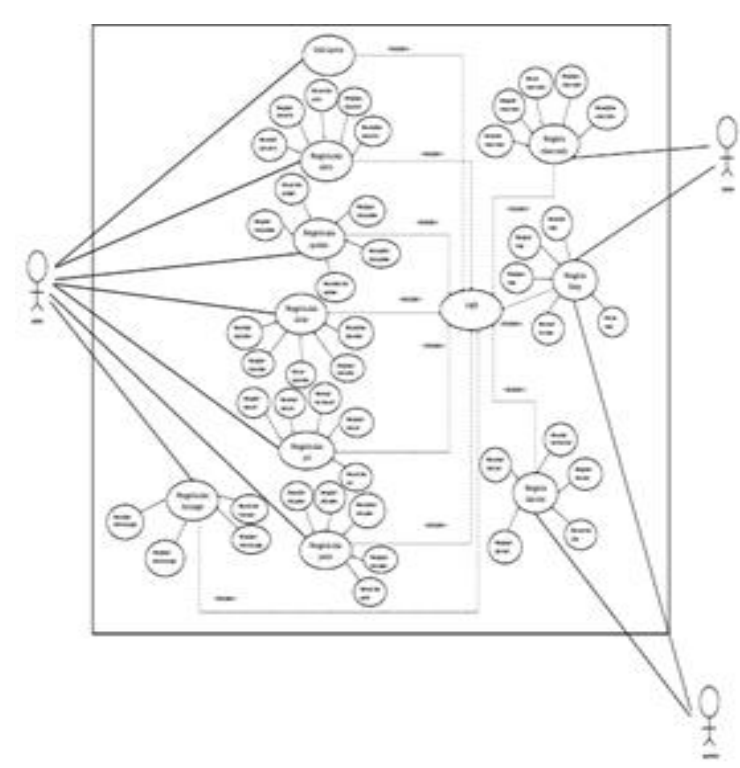

Sumber: Hasil Penelitian (2018)

Gambar 2. Use Case Diagram

2. Entity Relationship Diagram (ERD) Perancangan basis data menggunakan Entity Relationship Diagram (ERD) yaitu suatu model yang digunakan untuk menggambarkan mengidentifikasikan entitas yang menjelaskan data dan hubungan antar data. Perancangan ERD dapat dilihat pada gambar 3 berikut:

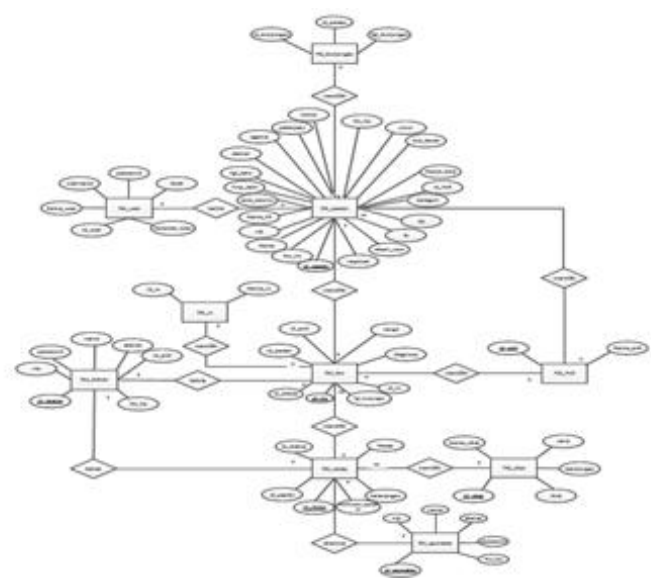

Sumber: Hasil Penelitian (2018)

Gambar 3. Entity Relationhip Diagram (ERD)

3. Class Diagram

Class diagram yaitu menggambarkan suatu struktur sistem yang dibangun berdasarkan diagram Use case dan diagram sequence yang telah dibuat. Dibawah ini merupakan class diagram dari sistem informasi rekam medis: 


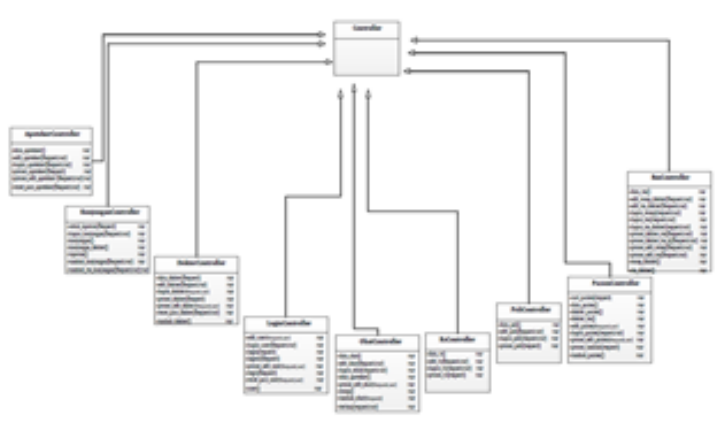

Sumber: Hasil Penelitian (2018)

Gambar 4. Class Diagram

D. Implementasi Antar Muka

Perancangan aplikasi memudahkan user dalam penggunaan sistem ini. Dialog Screen login berfungsi agar admin/dokter/apoteker/ dapat mendaftarkan diri.

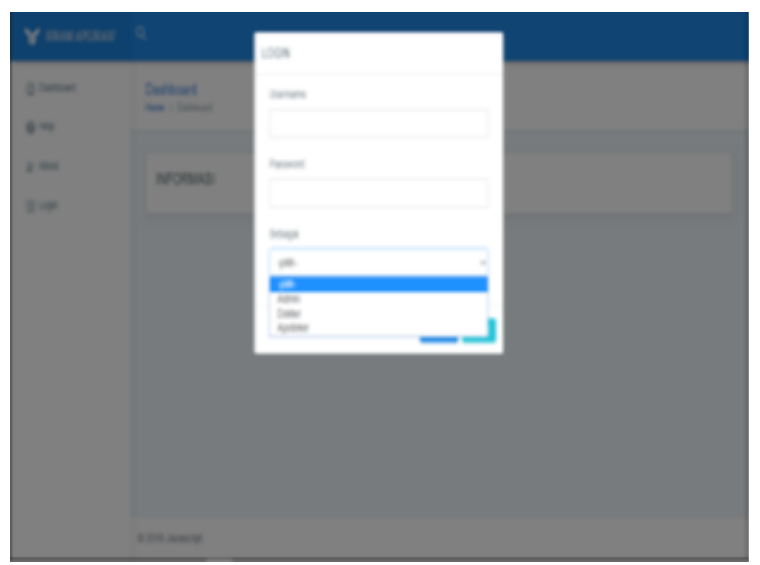

Sumber: Hasil Penelitian (2018)

Gambar 5. Tampilan Login Pengguna

Rancangan form master ini adalah halaman awal pada saat admin berhasil memasukkan username dan password maka tampilan inilah yang akan pertama kali muncul. Di form master ini terdapat beberapa menu yaitu menu dashboard yang merupakan tampilan awal, menu master yang berisi master admin, master pasien, master poli, master dokter, master apoteker, dan master rumah sakit bisa juga kita menambahkan sesuai dengan kebutuhan kita.

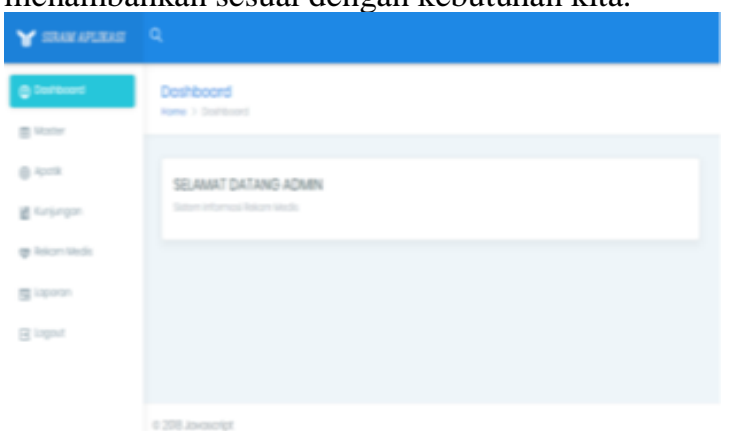

Sumber: Hasil Penelitian (2018)

Gambar 6. Tampilan Form Master Admin
Dalam form pasien,dokter hanya bisa mencari dan melihat data pasien yang telah didaftarkan oleh admin.

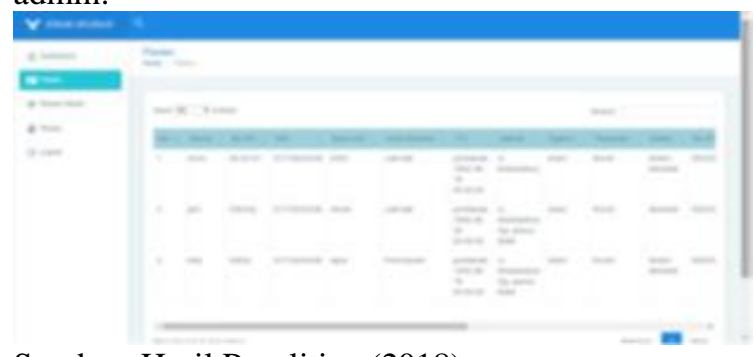

Sumber: Hasil Penelitian (2018)

Gambar 7. Tampilan Lihat Data Pasien

Dalam rekam medis,admin dapat melihat rekam medis yang telah diinputkan oleh dokter,sehingga admin dapat mengetahui tanggal kunjungan beserta dokter yang menangani pasien.

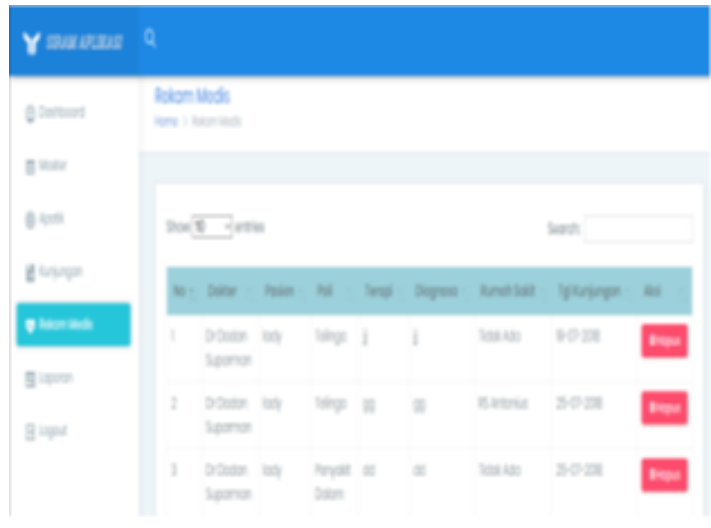

Sumber: Hasil Penelitian (2018)

Gambar 8. Tampilan Rekam Medis

\section{KESIMPULAN}

Aplikasi perancangan sistem informasi pasien rawat jalan ini merupakan sebuah aplikasi yang bermanfaat dalam media informasi sebagai bentuk perkembangan teknologi dan informasi. Selain itu, aplikasi ini mampu mempermudah dan mempercepat tugas admin, dokter, dan apoteker dalam proses pengelolaan data pasien, data rekam medis dan laporan data. Aplikasi ini juga mengurangi penggunaan kertas dalam penyimpanan datanya karena sudah tergantikan dengan menggunakan database sehingga data tidak mudah rusak dan hilang, serta mempermudah dalam proses pencarian datadata yang diperlukan.

Pasien tidak perlu membawa kertas resep untuk dibawa kebagian apoteker karena data resep sudah terkirim kebagian apoteker langsung dan laporan kunjungan pasien yang tersusun sesuai dengan data yang ada. 


\section{REFERENSI}

Abdulloh, R. (2017). Membuat Aplikasi Point of Sale dengan Laravel dan AJAX. Retrieved from https://play.google.com/store/books/details/Ro hi_Abdulloh_Membuat_Aplikasi_Point_of_Sa le_denga?id=nURGDwAAQBAJ

Aminuddin. (2015). Cara Efektif Belajar Framework Laravel. Yogyakarta: CV Lokomedia.

Aranita, E., \& Setiawan, B. (2017). PEMBUATAN APLIAKSI SISTEM INFORMASI PADA PUSKESMAS BERBASIS INTRANET/INTERNET. Retrieved from https://docplayer.info/35735279-Pembuatanapliaksi-sistem-informasi-pada-puskesmasberbasis-intranet-internet-eva-aranita-1-budisetiawan-2.html

Faruq, A. U. (2015). RANCANG BANGUN APLIKASI REKAM MEDIS POLIKLINIK UNIVERSITAS TRILOGI. Jurnal Informatika. Retrieved from http://journal.uad.ac.id/index.php/JIFO/article/ view/2043

Fridayanthie, E. W., \& Mahdiati, T. (2016). RANCANG BANGUN SISTEM INFORMASI PERMINTAAN ATK BERBASIS INTRANET (STUDI KASUS: KEJAKSAAN NEGERI RANGKASBITUNG). Jurnal Khatulistiwa Informatika. Retrieved from https://ejournal.bsi.ac.id/ejurnal/index.php/kha tulistiwa/article/view/1264

Pasaribu, J. S., \& Sihombing, J. (2017). PERANCANGAN SISTEM INFORMASI REKAM MEDIS PASIEN RAWAT JALAN BERBASIS WEB DENGAN FRAMEWORK YII DI KLINIK SEHAT MARGASARI BANDUNG. Teknologi Informasi Terapan. Retrieved from http://journal.widyatama.ac.id/index.php/jitter/ article/view/139

Salim, A., Setiadi, I., Kusuma, A. T., \& Lubis, O. B. (2013). PERANCANGAN SISTEM INFORMASI KOMUNITAS GAME BATTLEFIELD BERBASIS WEB. Retrieved from https://www.academia.edu/37314763/PERAN CANGAN_SISTEM_INFORMASI_KOMUN ITAS_GAME_BATTLEFIELD_BERBASIS WEB

Setyawan, E., \& Purnama, B. E. (2012). Pembangunan sistem informasi perpustakaan Sekolah dasar negeri (SDN) pacitan. Jurnal SPEED. Retrieved from https://ijns.org/journal/index.php/speed/article/ view/942

Sommervil, I. (2017). Software Engineering. London: Addison-Wesley.

Triyono, L. (2016). Sistem Informasi Akademik Kampus Berbasis Web dengan Laravel 5. Yogyakarta: CV Lokomedia. 